\title{
Assessment of electrocardiography, echocardiography, and heart rate variability in dynamic and static type athletes
}

This article was published in the following Dove Press journal:

International Journal of General Medicine

27 July 2012

Number of times this article has been viewed

\author{
Mehrnoush Toufan' \\ Babak Kazemi' \\ Fariborz Akbarzadeh' \\ Amin Ataei' \\ Majid Khalili² \\ 'Cardiovascular Research Center, \\ Tabriz University of Medical Sciences, \\ Tabriz, Iran; ${ }^{2}$ Azerbaijan National
}

Academy of Sciences, Baku, Azerbaijan
Correspondence: Majid Khalili AZI I4I,Vaxabzade St., Azerbaijan National Academy of Sciences,

Baku, Azerbaijan

Tel +994 I2 492562 I

Fax +994 I2 492562 I

Email khalili876@gmail.com
Background: Over the last two decades, morphological cardiac changes induced by athletic conditioning have been of great interest. Therefore, several studies have been orchestrated to delineate electrocardiography (ECG), echocardiography, and heart rate variability (HRV) findings in athletes.

Purpose: To assess the ECG, echocardiography, and HRV in a group of dynamic and static type athletes.

Methods: Fifty professional athletes (20 static and 30 dynamic exercise athletes) and 50 healthy nonathletes (control group) were recruited. Standard 12-lead ECG and transthoracic echocardiography was performed on all athletes and the control group. Through echocardiography, variables including left ventricular (LV) end-diastolic/systolic diameter, LV mass, and left atrial volume index were measured. In addition, both the athletes and the control group underwent ECG Holter monitoring for 15 minutes and several parameters related to HRV (time and frequency domain) were recorded.

Results: The most common ECG abnormalities among the athletes were sinus bradycardia and incomplete right bundle branch block. LV end-diastolic diameter and left atrial volume index were significantly greater in the dynamic athletes $(P<0.001)$. LV end-systolic diameter was significantly lower in the static group $(P<0.001)$. LV mass of the dynamic and static athletes was significantly greater than that of the controls $(P<0.001)$. Among the ECG Holter monitoring findings, the dynamic athletes had lower systolic blood pressure than the controls $(P=0.01)$. Heart rate was lowest in the control group $(P<0.001)$.

Conclusion: The most common ECG abnormalities among adolescent Iranian athletes were sinus bradycardia and incomplete right bundle branch block. Static exercise seemed to reduce LV end-systolic diameter, while dynamic exercise resulted in increased LV end-diastolic diameter and left atrial volume index. Additionally, Iranian athletes showed no differences in HRV parameters, excluding heart rate and systolic blood pressure, compared with the nonathletes.

Keywords: athlete's heart, electrocardiography, echocardiography, heart rate variability

\section{Introduction}

Over the last two decades, morphological cardiac changes induced by athletic conditioning have been of great interest. ${ }^{1}$ Several studies have been orchestrated to delineate features of the athlete's heart such as left ventricular (LV) and left atrial remodelling. ${ }^{2}$ Accordingly, relevant studies are still being performed using electrocardiography (ECG) and/or echocardiography to further shed light on these issues. Among these, some researchers have targeted their studies at comparing ECG and/or echocardiographic findings between dynamic (endurance) and static (strength) athletes. $^{3-6}$ However, some contrasting results exist in the literature in this regard. ${ }^{7}$ 
Furthermore, exercise is believed to alter a sympathovagal balance of the sinus node contributing in part to the heart rate changes in athletes. ${ }^{8}$ Nonetheless, it remains controversial whether these alterations in the autonomic function at rest, which is usually presented as bradycardia, are caused by attenuation of sympathetic tone and/or by enhanced vagal activity. ${ }^{9}$ Therefore, related investigations use heart rate variability (HRV) as a noninvasive method of providing information about vagal and sympathetic effects on the heart. ${ }^{10}$ To the best of the authors' knowledge, no single study has been hitherto performed to evaluate ECG, echocardiography, and HRV findings among athletes. Therefore, the aim of this study was to assess the ECG, echocardiography, and HRV in a group of Iranian dynamic and static type athletes and compare the related findings with those of healthy controls.

\section{Methods}

Between April 2010 and April 2011, 50 professional Iranian athletes introduced by the Physical Education Organization (Tehran, Iran) and 50 healthy nonathletes (as the control group) were recruited. The study was approved by the local medical ethical committee of Tabriz University of Medical Sciences (Tabriz, Iran). Informed consent was obtained from all participants prior to the study. The inclusion criteria were being a professional athlete; lack of any history of structural cardiac, cerebrovascular, chronic renal or hepatic diseases, malignancy, and pregnancy; and willingness to participate in the study.

Standard 12-lead ECG was performed on all athletes and the control group in the supine position after a few minutes of rest during quiet respiration and recorded at $25 \mathrm{~mm} /$ second. Thereafter, in the ECG analysis particular attention was paid to heart rate (beats/minute), PR interval (milliseconds), QRS duration (milliseconds), QT interval corrected for the heart rate (milliseconds), QT dispersion (difference between maximum and minimum QT interval) (seconds), P-wave morphologic abnormality (P-wave duration $>120$ milliseconds as measured in the lead with the widest $\mathrm{P}$-wave, amplitude $>0.25 \mathrm{mV}$, and terminal negative deflection in the right precordial leads $>0.1 \mathrm{mV}$ in depth), presence of Q-waves ( $\geq 2 \mathrm{~mm}$ in depth in at least two leads), $\mathrm{R}$ amplitude in precordial leads $\left(\mathrm{V}_{1}\right.$ and $\left.\mathrm{V}_{5}\right)$ (mm), Sokolow-Lyon voltage criterion for LV hypertrophy $\left(\mathrm{SV}_{1}+\mathrm{RV}_{5}>3.5 \mathrm{mV}\right)$, and T-wave inversion ( $\geq 2 \mathrm{~mm}$ in depth in at least two contiguous leads, with the exclusion of leads III and augmented vector right). In addition, all athletes and the control group underwent transthoracic echocardiography and related features including LV ejection fraction (LVEF), LV end-diastolic diameter (LVEDD), LV end-systolic diameter (LVESD), LV mass, left atrial volume index (LAVI), early mitral filling velocity/early diastolic mitral annular velocity ratio, and pulmonary arterial pressure (PAP) were recorded and evaluated. ${ }^{11,12}$ Moreover, both the athletes and the control group underwent ECG Holter monitoring for 15 minutes, and several parameters related to HRV including standard deviation of the normal-to-normal intervals and the square root of the mean squared difference of successive normal-to-normal intervals were recorded. Regarding the frequency domain, low frequency, high frequency, very low frequency, and ultra-low frequency were evaluated as well. ECG Holter monitoring was performed in the morning after 30 minutes of supine rest and the studied individuals had abstained from exercise for 12 hours (the night before testing). The sampling rate of the Holter monitors was $500 \mathrm{~Hz}$. The Holter images were scanned and analyzed with AB-180R Holter monitoring system (Advanced Biosensor Inc, Columbia, SC) after being manually edited to eliminate ectopic beats and noise signals by an experienced electrophysiologist (BK). The results of short-term recordings have been shown to correlate well with 24-hour recordings and are suitable for measuring changes over time. ${ }^{13}$ Furthermore, the prognostic value of short-term Holter recordings has been demonstrated for traditional HRV parameters. ${ }^{14,15}$

Data are presented as mean \pm standard deviation or as a percentage. All statistical analyses were performed with $\mathrm{IBM}^{\circledR}$ SPSS for Windows version 17 (SPSS Inc, Chicago, IL). To analyze the measured quantitative variables between the studied groups, one-way analysis of variance was applied followed by an additional post hoc test in cases of significance. To study the frequency changes of the qualitative variables, Chi-squared test or Fisher's exact test were used. A $P$ value less than 0.05 was considered statistically significant.

\section{Results}

In this study, 100 people with a mean age of $27.8 \pm 10.6$ years (range: 20-35 years) were recruited: 50 healthy nonathletes (control group) and 50 professional athletes. The professional athletes group consisted of 20 professional athletes in the field of static exercise (eg, weightlifting and body building) and 30 professional athletes in the field of dynamic exercise (eg, swimming, soccer, track and field, badminton). There was no difference in gender and age between the control and athletes group $(P>0.05$; Table 1$)$. Classical underlying risk 
Table I Demographic data and cardiovascular risk factors of the studied groups

\begin{tabular}{|c|c|c|c|c|}
\hline Variable & $\begin{array}{l}\text { Control group } \\
(n=50)\end{array}$ & $\begin{array}{l}\text { Static group } \\
(\mathrm{n}=20)\end{array}$ & $\begin{array}{l}\text { Dynamic group } \\
(n=30)\end{array}$ & $P$ value \\
\hline Age (years) & $26.5 \pm 4.7$ & $26.2 \pm 4.4$ & $26.7 \pm 4.02$ & 0.89 \\
\hline Family history of cardiovascular diseases & $3(6 \%)$ & $0(0)$ & $2(6 \%)$ & NA \\
\hline Smoking & $5(10 \%)$ & $4(8 \%)$ & $0(0)$ & NA \\
\hline Hyperlipidemia & $3(6 \%)$ & $2(10 \%)$ & $0(0)$ & NA \\
\hline Diabetes mellitus & $0(0)$ & $0(0)$ & $0(0)$ & NA \\
\hline Palpitation & $6(12 \%)$ & $3(15 \%)$ & I (3) & NA \\
\hline Dizziness & $3(6 \%)$ & I (5\%) & I (3\%) & NA \\
\hline Chest pain & $0(0)$ & $0(0)$ & $0(0)$ & NA \\
\hline History of syncope & $0(0)$ & $0(0)$ & $0(0)$ & NA \\
\hline
\end{tabular}

Note: Data presented as either mean \pm standard deviation or $n(\%)$.

Abbreviation: NA, not available.

factors for cardiac diseases and cardiac symptoms of the studied participants are presented in Table 1.

No significant difference was observed in the abnormal cases of ECG between the athletes and the control group; abnormal findings were present in 17 cases $(34 \%)$ of the athletes group and 14 cases (20\%) of the control group. The ECG qualitative and quantitative findings obtained from both groups are presented in Table 2. Among the ECG quantitative variables, there was a statistically significant difference regarding R-wave amplitude between static, dynamic, and control groups; the static athletes showed the highest $\mathrm{R}$-wave amplitude $(P<0.001)$.

The findings of the transthoracic echocardiography are presented in Table 3. LVEDD of the dynamic athletes was significantly greater than that of the control and static groups $(P<0.001)$. In addition, LVESD of the static group was significantly lower than that of the control and dynamic groups $(P<0.001)$. Furthermore, LV mass of the dynamic and static athletes was significantly greater than that of the controls $(P<0.001)$. On the other hand, LAVI in the dynamic athletes was significantly higher than that in the control and static groups $(P<0.001$ and $P=0.001$, respectively). There were no differences in other echocardiographic variables including LVEF, early mitral filling velocity/early diastolic mitral annular velocity ratio, and PAP between the groups (Table 3; $P>0.05$ ).

Among the findings obtained from the ECG Holter monitoring, heart rate and systolic blood pressure at rest were significantly different between the studied groups. The dynamic athletes had lower systolic blood pressure than the controls $(P=0.01$; Table 4$)$. Moreover, the heart rate was lowest in the control group compared with that in the dynamic and static athletes $(P<0.001$; Table 4). There were no differences in HRV parameters,

Table 2 Electrocardiographic findings in the studied groups

\begin{tabular}{|c|c|c|c|c|}
\hline Variable & $\begin{array}{l}\text { Control group } \\
(n=50)\end{array}$ & $\begin{array}{l}\text { Static group } \\
(n=20)\end{array}$ & $\begin{array}{l}\text { Dynamic group } \\
(n=30)\end{array}$ & $P$ value \\
\hline QTc interval (milliseconds) & $40 I .78 \pm 25.6 I$ & $399.93 \pm 29.61$ & $393.18 \pm 32.46$ & 0.42 \\
\hline QT dispersion (seconds) & $0.03 \pm 0.003$ & $0.03 \pm 0.004$ & $0.05 \pm 0.07$ & 0.12 \\
\hline QRS complex duration (milliseconds) & $72.01 \pm 12.46$ & $72.32 \pm 11.82$ & $72.5 \pm 11.44$ & 0.98 \\
\hline $\mathrm{R}$ amplitude $(\mathrm{mm})$ & $15.73 \pm 4.29$ & $27.27 \pm 5.66$ & $17.94 \pm 4.66$ & $<0.00 I^{\mathrm{a}}$ \\
\hline Sinus bradycardia $(H R<60$ beats/minute $)$ & $8(16 \%)$ & $10(50 \%)$ & $13(43 \%)$ & $0.03^{\mathrm{b}}$ \\
\hline Premature ventricular contraction & $4(8 \%)$ & $3(15 \%)$ & $4(13.3 \%)$ & NA \\
\hline $\mathrm{R}$ amplitude $>35 \mathrm{~mm}$ & $0(0)$ & $3(15 \%)$ & $0(0)$ & NA \\
\hline Inverted $\mathrm{T}$-waves & $0(0)$ & I (5\%) & $0(0)$ & NA \\
\hline Heart block (PR interval $>120$ milliseconds) & $0(0)$ & I (5\%) & I (3.3\%) & NA \\
\hline P morphology (RAA) & $3(6 \%)$ & $2(10 \%)$ & $6(20 \%)$ & NA \\
\hline P morphology (LAA) & $2(4 \%)$ & $2(10 \%)$ & I (3.3\%) & NA \\
\hline Q-waves & $0(0)$ & I (5\%) & $0(0)$ & NA \\
\hline Incomplete RBBB & $10(20 \%)$ & $6(30 \%)$ & II (36.6\%) & $0.04^{c}$ \\
\hline
\end{tabular}

Notes: Data presented as either mean \pm standard deviation or $\mathrm{n}(\%)$. ${ }^{2}$ Control versus static $(P<0.00 \mathrm{I})$, static versus dynamic $(P<0.00 \mathrm{I})$; ${ }^{\mathrm{b}}$ control versus static $(P=0.0 \mathrm{I})$ and dynamic $(P=0.03)$; ${ }^{c}$ control versus static $(P=0.04)$ and dynamic $(P=0.03)$.

Abbreviations: HR, heart rate; LAA, left atrial appendage; NA, not available; QTc, QT interval corrected for the heart rate; RAA, right atrial appendage; RBBB, right bundle branch block. 
Table 3 Echocardiographic variables in the studied groups

\begin{tabular}{|c|c|c|c|c|}
\hline Variable & $\begin{array}{l}\text { Control group } \\
(n=50)\end{array}$ & $\begin{array}{l}\text { Static group } \\
(n=20)\end{array}$ & $\begin{array}{l}\text { Dynamic group } \\
(n=30)\end{array}$ & $P$ value \\
\hline LVEF (\%) & $59.18 \pm 3.6$ & $61.55 \pm 4.5$ & $61.50 \pm 3.3$ & 0.09 \\
\hline LVEDD (cm) & $4.49 \pm 0.38$ & $4.71 \pm 0.43$ & $5.4 \pm 0.32$ & $<0.001^{a}$ \\
\hline LVESD (cm) & $3.18 \pm 0.32$ & $2.81 \pm 0.33$ & $3.36 \pm 0.38$ & $<0.001^{\mathrm{b}}$ \\
\hline LV mass $(\mathrm{g})$ & $154.5 \pm 29$ & $224.6 \pm 40.3$ & $225.8 \pm 51.2$ & $<0.00 \mathrm{I}^{\mathrm{c}}$ \\
\hline LAVI $\left(\mathrm{mL} / \mathrm{m}^{2}\right)$ & $31.35 \pm 5.64$ & $35.47 \pm 12.11$ & $45.49 \pm 11.36$ & $<0.00 \mathrm{l}^{\mathrm{d}}$ \\
\hline $\mathrm{E} / \mathrm{E}^{\prime}$ (cm/second) & $5.02 \pm 0.44$ & $5.01 \pm 0.69$ & $4.65 \pm 1.06$ & 0.07 \\
\hline
\end{tabular}

Notes: Data presented as mean \pm standard deviation. ${ }^{\mathrm{a} C}$ Control versus static $(P<0.00 \mathrm{I})$ and dynamic $(P<0.00 \mathrm{I})$, static versus dynamic $(P<0.00 \mathrm{I})$; ${ }^{\mathrm{b}} \mathrm{control}$ versus static $(P<0.00 \mathrm{I})$ and dynamic $(P<0.00 \mathrm{I})$, static versus dynamic $(P<0.00 \mathrm{I})$; ' ${ }^{\mathrm{c}} \mathrm{Control}$ versus static $(P<0.00 \mathrm{I})$ and dynamic $(P<0.00 \mathrm{I})$; ${ }^{\mathrm{d}} \mathrm{control}$ versus dynamic $(P<0.00 \mathrm{I})$, static versus dynamic $(P=0.001)$.

Abbreviations: E/E', early mitral filling velocity/early diastolic mitral annular velocity ratio; LAVI, left atrial volume index; LV mass, left ventricular mass; LVEDD, left ventricular end-diastolic diameter; LVEF, left ventricular ejection fraction; LVESD, left ventricular end-systolic diameter.

both time and frequency domain, between the groups (Table 4; $P>0.05$ ).

\section{Discussion}

In recent years, numerous medical reports have been describing diverse changes in ECG of professional athletes, most of which are due to a physiological adaptation of the athlete's heart to the conditions associated with physical activities. ${ }^{16,17}$ Abnormal ECG is more frequent among athletes compared with nonathletes, with a wide range of changes varying from $10 \%-50 \% .{ }^{16}$ In a study carried out by Sharma et al studying the ECG changes between athletes and nonathletes, sinus bradycardia and sinus arrhythmia were reported in $80 \%$ and $52 \%$ of the athletes, respectively. ${ }^{18}$ Magalski et al highlighted that the most important ECG abnormalities accompanied with a high risk in athletes are deep Q-wave and inverted T-wave, which were, however, rare $(<5 \%) .{ }^{19}$ Deep inverted $\mathrm{T}$-waves are one of the most important alarming indicators of cardiomyopathy in athletes. ${ }^{20}$ In the current study, deep Q-wave and inverted
T-wave was present in $2 \%$ of the athletes, each accounting for a very low percentage of the abnormal ECG findings in athletes. This finding is similar to that of previous studies. ${ }^{19,21}$ Consistent with previous studies, the most common ECG finding in the current study was sinus bradycardia. ${ }^{18,20,22}$ There is a consensus on the most common ECG changes in athletes: sinus bradycardia, first degree heart block, and incomplete right bundle branch block. ${ }^{23}$ Similarly, sinus bradycardia and incomplete right bundle branch block were the most common ECG abnormalities in the athletes group of the current study. Furthermore, tall R-wave was only detected in the static athletes, which is consistent with the findings of Bialy et al's study. ${ }^{24}$ This finding is suggestive of cardiac adaptation of the static athletes for their particular type of exercise, ie, strength training exercises.

Previous studies have confirmed that adaptive changes of the heart muscle, such as symmetrical hypertrophy and cardiac volume changes, are based on the exercise activity of the athletes, and hemodynamic changes and requirements are the major factors contributing to the changes in the

Table 4 Heart rate variability variables in the studied groups

\begin{tabular}{|c|c|c|c|c|}
\hline Variable & $\begin{array}{l}\text { Control group } \\
(n=50)\end{array}$ & $\begin{array}{l}\text { Static group } \\
(n=20)\end{array}$ & $\begin{array}{l}\text { Dynamic group } \\
(n=30)\end{array}$ & $P$ value \\
\hline Systolic blood pressure (mmHg) & $127.34 \pm 7.3$ & $123.75 \pm 13.16$ & $120.42 \pm 11.78$ & $0.0 \mathrm{I}^{\mathrm{a}}$ \\
\hline Diastolic blood pressure $(\mathrm{mmHg})$ & $78.1 \pm 8.7$ & $79.3 \pm 11.1$ & $74.59 \pm 7.5$ & 0.13 \\
\hline Heart rate (beats/minute) & $73.4 \pm 7.76$ & $61.9 \pm 8.38$ & $58.86 \pm 8.68$ & $<0.00 I^{\mathrm{b}}$ \\
\hline SDNN (milliseconds) & $72.22 \pm 27.29$ & $75.68 \pm 44.68$ & $74.67 \pm 26.58$ & 0.89 \\
\hline RMSSD (milliseconds) & $46.88 \pm 31.24$ & $59.18 \pm 37.46$ & $65.79 \pm 40.51$ & 0.06 \\
\hline HRV index & $15.47 \pm 3.89$ & $15.37 \pm 5.08$ & $16.38 \pm 3.4$ & 0.56 \\
\hline ULF $(\mathrm{Hz})$ & $46.43 \pm 36.61$ & $53.22 \pm 37.18$ & $49.07 \pm 38.3$ & 0.78 \\
\hline $\operatorname{VLF}(\mathrm{Hz})$ & $234.63 \pm 78.7$ & $215.5 \pm 85.49$ & $213.1 \pm 84.12$ & 0.45 \\
\hline $\mathrm{LF}(\mathrm{Hz})$ & $225.3 \pm 64.37$ & $228.35 \pm 73.28$ & $224.43 \pm 72.54$ & 0.1 \\
\hline $\mathrm{HF}(\mathrm{Hz})$ & $131.75 \pm 53.49$ & $122.99 \pm 35.18$ & $126.06 \pm 35.75$ & 0.73 \\
\hline
\end{tabular}

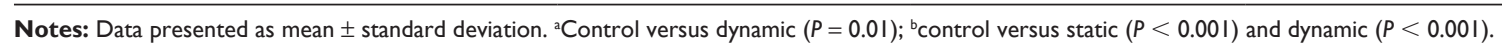

Abbreviations: HF, high frequency; HRV, heart rate variability; LF, low frequency; RMSSD, square root of the mean squared difference of successive normal-to-normal intervals; SDNN, standard deviation of the normal-to-normal intervals; ULF, ultra-low frequency; VLF, very low frequency. 
heart muscle and structure of the heart in athletes..$^{25}$ In an echocardiographic study of athletes performed by Bialy et al LV mass of the dynamic athletes increased compared with the nonathletes. ${ }^{24}$ In the current study, LV mass of dynamic and static athletes was significantly greater than that in nonathletes. This finding was previously reported by Abinader et $\mathrm{al}^{26}$ and $\mathrm{D}$ 'Andrea et al. ${ }^{3}$ Although the current study did not result in a difference between static and dynamic athletes with regard to LV mass, Venckunas et al indicated that LV mass was lower in static athletes compared with dynamic athletes. ${ }^{7}$ During dynamic exercise, the LV withstands repetitive stress, which leads to an increase in LV mass. In addition, the current study revealed that LVESD was lower in static athletes and LVEDD was greater in dynamic athletes considering their increased hemodynamic requirements. Abinader et $\mathrm{al}^{26}$ and D'Andrea et $\mathrm{al}^{5,6,27}$ reported similar findings in this regard. Moreover, in the current study, LAVI was significantly greater in the dynamic athletes compared with the static athletes and nonathletes. This finding is similar to that of previous studies by D'Andrea et al. ${ }^{27-29}$ In addition, the current results indicate similar LVEF values in the nonathletes, static athletes, and dynamic athletes. Likewise, D'Andrea et al found no difference between the static and dynamic groups with regard to LVEF. 5,6,27-29 Furthermore, the current study failed to detect any difference in PAP between the studied groups. In contrast, recent investigations by D'Andrea et al indicate a higher PAP in dynamic athletes. ${ }^{4,6}$

One of the long-term effects of exercise is a positive increase in parasympathetic activities in the autonomic nervous system, which can be traced using parameters such as standard deviation of the normal-to-normal intervals (HRV) and square root of the mean squared difference of successive normal-to-normal intervals. ${ }^{25}$ During dynamic exercise, the heart rate increases which is due to parasympathetic blockade and increase in sympathetic activity; however, the dominance of the parasympathetic system is significant in athletes. ${ }^{30}$ The current study revealed that the heart rate and systolic blood pressure at rest were lower in the athletes compared with the control group. These findings are similar to those of previous studies. ${ }^{24,31,32}$ With regard to the HRV parameters, previous studies indicated a significant increase in HRV in professional athletes. ${ }^{31-33}$ In other studies on the autonomic nervous system using HRV analysis, a shift in the cardiac autonomic balance towards the dominance of the sympathetic system was noted. ${ }^{34-36}$ On the other hand, in a study carried out by Raczak et al, no increase in adrenergic activity was reported despite an increase in activity. ${ }^{25}$
Lower sample sizes in previous studies may have contributed to the observed differences in results. In the current study, no significant difference was observed between the athletes and nonathletes regarding HRV. The sampling rate of Holter monitoring was $500 \mathrm{~Hz}$ in the current study, a rate sufficient for measuring very low frequency, low frequency, and high frequency domains of HRV during short-term recording. ${ }^{37}$ However, the measurement of ultra low frequency requires more recording time. This can be regarded as a limitation in the current study.

\section{Conclusion}

The present investigation found that the most common ECG abnormalities among adolescent Iranian athletes were sinus bradycardia and incomplete right bundle branch block. In addition, according to their increased hemodynamic requirements, static exercise seemed to reduce LVESD. On the other hand, dynamic exercise resulted in increased LVEDD diameter and LAVI. Additionally, Iranian athletes showed no differences in HRV parameters, excluding heart rate and systolic blood pressure, compared with the nonathletes.

\section{Disclosure}

The authors report no conflicts of interest in this work.

\section{References}

1. Pelliccia A, Di Paolo FM, De Blasiis E, et al. Prevalence and clinical significance of aortic root dilation in highly trained competitive athletes. Circulation. 2010;122(7):698-706.

2. Maron BJ, Pelliccia A. The heart of trained athletes: cardiac remodeling and the risks of sports, including sudden death. Circulation. 2006; 114(15):1633-1644.

3. D'Andrea A, Cocchia R, Riegler L, et al. Aortic stiffness and distensibility in top-level athletes. J Am Soc Echocardiogr. 2012;25(5):561-567.

4. D'Andrea A, Riegler L, Golia E, et al. Range of right heart measurements in top-level athletes: the training impact. Int J Cardiol. July 5, 2011. [Epub ahead of print.]

5. D'Andrea A, Cocchia R, Riegler L, et al. Left ventricular myocardial velocities and deformation indexes in top-level athletes. J Am Soc Echocardiogr. 2010;23(12):1281-1288.

6. D'Andrea A, Naeije R, D'Alto M, et al. Range in pulmonary artery systolic pressure among highly trained athletes. Chest. 2011;139(4): 788-794.

7. Venckunas T, Vasiliauskas D, Marcinkeviciene JE, Grizas V, Stasiulis A, Malkova D. Strongmen sport is associated with larger absolute heart size and impaired cardiac relaxation. J Strength Cond Res. 2011; 25(10):2919-2925.

8. Martinelli FS, Chacon-Mikahil MP, Martins LE, et al. Heart rate variability in athletes and nonathletes at rest and during head-up tilt. Braz J Med Biol Res. 2005;38(4):639-647.

9. Goldsmith RL, Bigger JT Jr, Steinman RC, Fleiss JL. Comparison of 24-hour parasympathetic activity in endurance-trained and untrained young men. J Am Coll Cardiol. 1992;20(3):552-558.

10. Martinmaki K, Rusko H, Kooistra L, Kettunen J, Saalasti S. Intraindividual validation of heart rate variability indexes to measure vagal effects on hearts. Am J Physiol Heart Circ Physiol. 2006;290(2): H640-H647. 
11. Khosroshahi HT, Habibi-Asl B, Toufan M, Ghabili K, Safarpour S. Effects of oral L-carnitine on cardiac abnormalities of maintenance hemodialysis patients. Biomed Int. 2010;1(1):30-33.

12. Etemadi J, Zolfaghari H, Firoozi R, et al. Unexplained pulmonary hypertension in peritoneal dialysis and hemodialysis patients. Rev Port Pneumol. 2012;18(1):10-14.

13. Bigger JT Jr, Fleiss JL, Rolnitzky LM, Steinman RC, Schneider WJ. Time course of recovery of heart period variability after myocardial infarction. J Am Coll Cardiol. 1991;18(7):1643-1649.

14. Perkiomaki JS, Zareba W, Kalaria VG, Couderc J, Huikuri HV, Moss AJ. Comparability of nonlinear measures of heart rate variability between long- and short-term electrocardiographic recordings. Am J Cardiol. 2001;87(7):905-908.

15. La Rovere MT, Pinna GD, Maestri R, et al. Short-term heart rate variability strongly predicts sudden cardiac death in chronic heart failure patients. Circulation. 2003;107(4):565-570.

16. Pelliccia A, Culasso F, Di Paolo FM, et al. Prevalence of abnormal electrocardiograms in a large, unselected population undergoing preparticipation cardiovascular screening. Eur Heart J. 2007;28(16): 2006-2010.

17. Pelliccia A, Di Paolo FM, Quattrini FM, et al. Outcomes in athletes with marked ECG repolarization abnormalities. NEngl J Med. 2008;358(2): $152-161$.

18. Sharma S, Whyte G, Elliott $P$, et al. Electrocardiographic changes in 1000 highly trained junior elite athletes. Br J Sports Med. 1999;33(5): 319-324.

19. Magalski A, Maron BJ, Main ML, et al. Relation of race to electrocardiographic patterns in elite American football players. J Am Coll Cardiol. 2008;51(23):2250-2255.

20. Pelliccia A, Maron BJ, Culasso F, et al. Clinical significance of abnormal electrocardiographic patterns in trained athletes. Circulation. 2000; 102(3):278-284.

21. Le VV, Wheeler MT, Mandic S, et al. Addition of the electrocardiogram to the preparticipation examination of college athletes. Clin J Sport Med. 2010;20(2):98-105.

22. Holly RG, Shaffrath JD, Amsterdam EA. Electrocardiographic alterations associated with the hearts of athletes. Sports Med. 1998; 25(3):139-148

23. Corrado D, Pelliccia A, Heidbuchel H, et al. Recommendations for interpretation of 12-lead electrocardiogram in the athlete. Eur Heart J. 2010;31(2):243-259.

24. Bialy D, Derkacz A, Nowosad H, et al. Electrocardiography and echocardiography in athletic heart imagining. Biol Sport. 2003;20(3): 195-208.
25. Raczak G, Danilowicz-Szymanowicz L, Kobuszewska-Chwirot M, Ratkowski W, Figura-Chmielewska M, Szwoch M. Long-term exercise training improves autonomic nervous system profile in professional runners. Kardiol Pol. 2006;64(2):135-140.

26. Abinader EG, Sharif D, Sagiv M, Goldhammer E. The effects of isometric stress on left ventricular filling in athletes with isometric or isotonic training compared to hypertensive and normal controls. Eur Heart J. 1996;17(3):457-461.

27. D'Andrea A, Limongelli G, Caso P, et al. Association between left ventricular structure and cardiac performance during effort in two morphological forms of athlete's heart. Int J Cardiol. 2002;86(2-3): 177-184.

28. D'Andrea A, Riegler L, Cocchia R, et al. Left atrial volume index in highly trained athletes. Am Heart J. 2010;159(6):1155-1161.

29. D'Andrea A, Cocchia R, Riegler L, et al. Aortic root dimensions in elite athletes. Am J Cardiol. 2010;105(11):1629-1634.

30. Aubert AE, Seps B, Beckers F. Heart rate variability in athletes. Sports Med. 2003;33(12):889-919.

31. Aubert AE, Beckers F, Ramaekers D. Short-term heart rate variability in young athletes. J Cardiol. 2001;37(Suppl 1):85-88.

32. Christoforidi V, Koutlianos N, Deligiannis P, Kouidi E, Deligiannis A. Heart rate variability in free diving athletes. Clin Physiol Funct Imaging. 2012;32(2):162-166.

33. Hedelin R, Wiklund U, Bjerle P, Henriksson-Larsen K. Pre- and postseason heart rate variability in adolescent cross-country skiers. Scand J Med Sci Sports. 2000;10(5):298-303.

34. Iellamo F, Legramante JM, Pigozzi F, et al. Conversion from vagal to sympathetic predominance with strenuous training in high-performance world class athletes. Circulation. 2002;105(23):2719-2724.

35. Pichot V, Busso T, Roche F, et al. Autonomic adaptations to intensive and overload training periods: a laboratory study. Med Sci Sports Exerc. 2002;34(10):1660-1666.

36. Portier H, Louisy F, Laude D, Berthelot M, Guezennec CY. Intense endurance training on heart rate and blood pressure variability in runners. Med Sci Sports Exerc. 2001;33(7):1120-1125.

37. Task Force of the European Society of Cardiology and the North American Society of Pacing and Electrophysiology. Heart rate variability: standards of measurement, physiological interpretation and clinical use. Circulation. 1996;93(5):1043-1065.
International Journal of General Medicine

\section{Publish your work in this journal}

The International Journal of General Medicine is an international, peer-reviewed open-access journal that focuses on general and internal medicine, pathogenesis, epidemiology, diagnosis, monitoring and treatment protocols. The journal is characterized by the rapid reporting of reviews, original research and clinical studies across all disease areas.

\section{Dovepress}

A key focus is the elucidation of disease processes and management protocols resulting in improved outcomes for the patient.The manuscript management system is completely online and includes a very quick and fair peer-review system. Visit http://www.dovepress.com/ testimonials.php to read real quotes from published authors. 